\title{
Effect of Modified Ultrafiltration on Acute Kidney Injury Biomarkers and Clinical Outcome in Adult Patients Undergoing Valvular Heart Surgery
}

Hani Mohammed Ahmed Raslan"1, Ahmed Al-Saied Abdul Rahman², Huda Fahmy Mahmoud ${ }^{1}$ ${ }^{1}$ Department of Anaesthesia and Intensive Care, Faculty of Medicine, Sohag University, Sohag, ${ }^{2}$ Department of Anaesthesia and Intensive care, Faculty of Medicine, Aswan University, Aswan, Egypt

*Corresponding author: Hani Mohammed Ahmed Raslan, Mobile: (+20) 01014734266,

\author{
E-Mail: hani.raslan@ymail
}

\begin{abstract}
Background: Cardiac surgery associated with acute kidney injury (CSA-AKI) is a common and serious postoperative complication of cardiac surgery requiring cardiopulmonary bypass (CPB). CSA-AKI varies between $7 \%$ and $40 \%$ in large cohorts undergoing a variety of cardiac surgical procedures and is associated independently with increased morbidity and mortality.

Objective: Our study aimed to investigate the effect of using modified ultrafiltration on acute kidney injury by using the levels of AKI biomarkers (serum creatinine and NGAL) in adult patients with no previous chronic renal disease undergoing valvular heart surgery using cardiopulmonary bypass.

Patients and Methods: This prospective observational study was conducted at the cardiothoracic surgery unit, Kasr AL-Ainy hospital from February 2017 to July 2017 on 40 patients who underwent valve replacement surgery using cardiopulmonary bypass. The patients were randomly allocated into two groups: Group 1: Non-MUF group. Group 2: MUF group.

Results: Regarding serum creatinine, the preoperative and $2 \mathrm{~h}$ postoperative levels were not statistically different between the two studied groups $(\mathrm{P}>0.05)$, while in the non-MUF group, there was a significant increase $(\mathrm{P}<0.001)$ in the $2 \mathrm{~h}$. post-operative creatinine level compared with the pre-operative level. In the MUF group, there was no significant difference $(\mathrm{P}>0.05)$ between AKI and non-AKI patients in preoperative levels while the postoperative creatinine levels were significantly higher $(\mathrm{P}<0.04)$ in AKI than non-AKI patients.

Conclusion: AKI after cardiac surgery is independently associated with a significant increase in morbidity, mortality, and health-care costs.
\end{abstract}

Keywords: Modified ultrafiltration, Acute kidney injury biomarkers, Valvular heart surgery

\section{INTRODUCTION}

Acute kidney injury (AKI) after cardiac surgery occurs from a rapid deterioration in renal function following cardiac surgery expressed as a significant decrease in glomerular filtration rate (GFR). The reported prevalence of cardiac surgeryassociated acute kidney injury (CSA-AKI) is up to $30 \%$ and is independently associated with an increase of morbidity and mortality ${ }^{(1)}$.

Patients with AKI who receive renal replacement therapy (RRT) are $>3$ times more likely to develop ESRD than those who do not. This rise in the number of patients who receive treatment for ESRD is a global phenomenon associated with considerable patient costs, effects on quality of life, and economic impact on society as a whole. In developing countries, most people with kidney failure have insufficient access to dialysis and/or kidney transplantation ${ }^{(2)}$.

Consequently, the development of effective approaches to the prevention, early recognition, and management of AKI is necessary to reduce the burden of CKD and ESRD ${ }^{(3)}$.

Cardiac surgery has long been used to study AKI because of the opportunity to prospectively follow patients before and after a well-timed ischemic renal insult (cardiopulmonary bypass). For this reason, several blood, and urinary proteins have been investigated in this setting, and found to serve as biomarkers of AKI after cardiac surgery, including neutrophil gelatinase-associated lipocalin (NGAL), IL-18, cystatin C (CysC), kidney injury molecule-1 (KIM-1), and liver fatty acid-binding protein ${ }^{(4)}$.

For over a century, the measurement of serum creatinine, a biomarker of glomerular filtration, has been a mainstay of clinical laboratory testing and served as the primary method for quantifying renal function. These creatinine-based estimates of renal function are focused on glomerular filtration and do not adequately account for structural renal tubular injury, which may be extensive in the setting of AKI. The past several years have seen a large number of investigations seeking novel biomarkers of AKI ${ }^{(5)}$.

\footnotetext{
AIM OF THE STUDY

Our study aimed to investigate the effect of using modified ultrafiltration on acute kidney injury by using the levels of AKI biomarkers (serum creatinine and NGAL) in adult patients with no previous chronic renal disease undergoing valvular heart surgery using cardiopulmonary bypass.
} 


\section{PATIENTS AND METHODS}

This prospective observational study was conducted over 6 months (from February to July 2017) at the Cardiothoracic Surgery Unit, Kasr AL-Ainy Hospitals. The study included 40 patients undergoing routine valve replacement surgery using cardiopulmonary bypass.

Inclusion criteria: Adult patients ( $>16$ years). Patients undergoing open valvular heart surgery using CPB.

Exclusion criteria: Patients ( $>16$ years). Emergency or redo surgery. ASA Class IV patients. Preoperative renal dysfunction or chronic renal disease. Poor preoperative ventricular function.

\section{Ethical Consideration:}

The protocol was approved by the Aswan Faculty of Medicine Ethical Committee and written consent was obtained from each patient.

\author{
The patients were randomly allocated into two \\ groups: \\ - Group1: MUF group \\ - Group 2: Non-MUF group.
}

\section{Anesthesia Technique:}

- Patients scheduled for cardiac surgery are usually fully investigated for their cardiac status. However, the presence of non-cardiac medical illnesses and routine general anesthetic assessment should not be overlooked including routine laboratory investigation and arrangements of blood products.

- All patients were premeditated with 5-10 mg oral midazolam the night before surgery.

- After transferring the patient to the preoperative holding area, the arterial line (radial artery) was introduced in the patient's non-dominant hand after reviewing the duplex study.

- Induction was made using propofol (1-2mglkg),

- Atracurium $(0.4 \mathrm{mg} \mathrm{kg})$,

- Fentanyl (50 microgram increments)

- After tracheal intubation, the patients were mechanically ventilated to give a tidal volume (6$8 \mathrm{ml} / \mathrm{kg}$ )

- Maintenance of anesthesia was achieved by isoflurane in $60 \%$ oxygen and atracurium infusion ( 0.3 to $0.6 \mathrm{mg} / \mathrm{kg} /$ hour).

- $\quad$ PB was conducted on all cases using membrane oxygenator, non-occlusive roller pumps, and priming of all cases was done with crystalloids. Myocardial protection was achieved using a cardioplegia solution in a dose of $20 \mathrm{ml} / \mathrm{kg}$ and Modified ultrafiltration was performed after getting off bypass for about15-20minutes.patients were transferred to the ICU intubated.

\section{The technique of modified ultrafiltration:}

In this method, the arterial line is connected to the inlet of the ultrafilter and the venous line is connected to the outlet of the ultrafilter in the CPB circuit. The inlet of the filter was clamped throughout the CPB. As the patient is separated from the CPB, the clamp is removed from the inlet of the filter, allowing the blood to flow through the arterial line to the filter $(10-15 \mathrm{~mL} / \mathrm{kg} / \mathrm{min})$, and finally from the cardioplegic cannula, as a venous line returns to the right atrium.

\section{Indicator detection:}

NGAL and creatinine levels were detected using ELISA according to the manufacturer's instructions. In brief: i) blood stored at $-80^{\circ} \mathrm{C}$ was thawed at room temperature $\left(20^{\circ} \mathrm{C}\right)$; ii) samples and standards were diluted (dilution ratio 1:5) and transferred to the plate; iii) samples were incubated in the plate for $30 \mathrm{~min}$ at $37^{\circ} \mathrm{C}$ and then washed with phosphate-buffered saline (PBS) 5 times for $15 \mathrm{sec}$ for each time; iv) enzyme-conjugated reagent $(50 \mu \mathrm{l})$ was added and incubated at $37^{\circ} \mathrm{C}$ for $30 \mathrm{~min}$, followed by four 15-sec washes; v) color developer A and B were added and the samples were incubated at room temperature in the dark for $15 \mathrm{~min}$. The termination solution was then added, and the OD value at $450 \mathrm{~nm}$ was measured using a microplate reader within $15 \mathrm{~min}$. These readings were used to calculate NGAL and Scr levels.

\section{Statistical analysis}

Data entry and its analysis were done using SPSS version 24 (Statistical Package for Social Science). Data were presented as the number, percentage, mean, standard deviation. Chi-square test and Fisher Exact test were used to compare qualitative variables. An independent sample t-test was used to compare quantitative variables between groups. Pvalue considered statistically significant when $\mathrm{P}<$ 0.05 .

\section{RESULTS}

Regarding demographic and clinical data, there were no significant differences $(\mathrm{P}>0.05)$ between the studied groups in age, gender, weight, height, BMI, type of operation, aortic cross-clamp time, or intraoperative UOP, while there was a significant increase $(\mathrm{P}<0.05)$ in the duration of $\mathrm{CPB}$ in the MUF group compared with the non-MUF group as shown in Table (1). 
Table (1): Demographic and clinical data of the studied groups

\begin{tabular}{|c|c|c|c|}
\hline Item & $\begin{array}{c}\text { G1" Non-MUF" } \\
(\mathrm{n}=20)\end{array}$ & $\begin{array}{c}\text { G2"MUF" } \\
(n=20)\end{array}$ & P-value \\
\hline $\begin{array}{l}\text { 1-Age "years" } \\
\text { Mean } \pm \text { SD } \\
\text { Range } \\
\text { 2-gender: } \\
\text { - Male } \\
\text { - } \text { Female } \\
\text { 3-Weight "kg" } \\
\text { Mean } \pm \text { SD } \\
\text { Range } \\
\text { 4-Height "cm" } \\
\text { Mean } \pm \text { SD } \\
\text { Range } \\
\text { 5-BMI "kg/m" } \\
\text { Mean } \pm \text { SD } \\
\text { Range } \\
\text { 6-Type of operation: } \\
\text { MR } \\
\text { AR } \\
\text { MR AR } \\
\text { 7- Duration of CPB" min" } \\
\text { Mean } \pm \text { SD } \\
\text { Range } \\
\text { 8-Aortic cross-clamp time" min" } \\
\text { Mean } \pm \text { SD } \\
\text { Range } \\
\text { 9-Intraoperative UOP } \\
\text { Mean } \pm \text { SD } \\
\text { Range }\end{array}$ & $\begin{array}{c}33.00 \pm 7.32 \\
(22.0-49.0) \\
\\
5(25.0 \%) \\
15(75.0 \%) \\
\\
72.95 \pm 6.41 \\
(64.0-89.0) \\
\\
168.60 \pm 5.19 \\
(160.0-178.0) \\
\\
25.64 \pm 1.64 \\
(22.41-28.73) \\
\\
17(85.0 \%) \\
1(5.0 \%) \\
2(10.0 \%) \\
\\
82.25 \pm 16.02 \\
(67.0-98.0)\end{array}$ & $\begin{array}{c}30.80 \pm 6.69 \\
(22.0-46.0) \\
\\
5(25.0 \%) \\
15(75.0 \%) \\
\\
70.30 \pm 8.02 \\
(58.0-88.0) \\
\\
166.0 \pm 5,82 \\
(156.0-179.0) \\
\\
25.19 \pm 1.87 \\
(22.41-28.26) \\
\\
15(75.0 \%) \\
5(25.0 \%) \\
0.0 \\
93.35 \pm 6.92 \\
(69.0-128.0)\end{array}$ & $\begin{array}{l}\mathrm{P}=0.323 \mathrm{n} . \mathrm{s} \\
\mathrm{P}=0.642 \mathrm{n} . \mathrm{s} \\
\mathrm{P}=0.256 \mathrm{n} . \mathrm{s} \\
\mathrm{P}=0.322 \mathrm{n} . \mathrm{s} \\
\mathrm{P}=0.424 \mathrm{n} . \mathrm{s} \\
\mathrm{P}=0.092 \mathrm{n} . \mathrm{s}\end{array}$ \\
\hline
\end{tabular}

Abbreviations: Group1: without modified ultra-filtration; Group2: with modified ultrafiltration. BMI: body mass index, MR: Mitral valve replacement, AR: Aortic valve replacement, CPB: Cardiopulmonary bypass, UOP: Urine output. P-value is considered significant at $<0.05$. There was no significant difference between the two studied groups regarding HR, SBP, $\mathrm{DBP}$, and $\mathrm{SPO}_{2}(\mathrm{P}>0.05)$ as in Table 2.

Table (2): Perioperative hemodynamic data in the studied groups

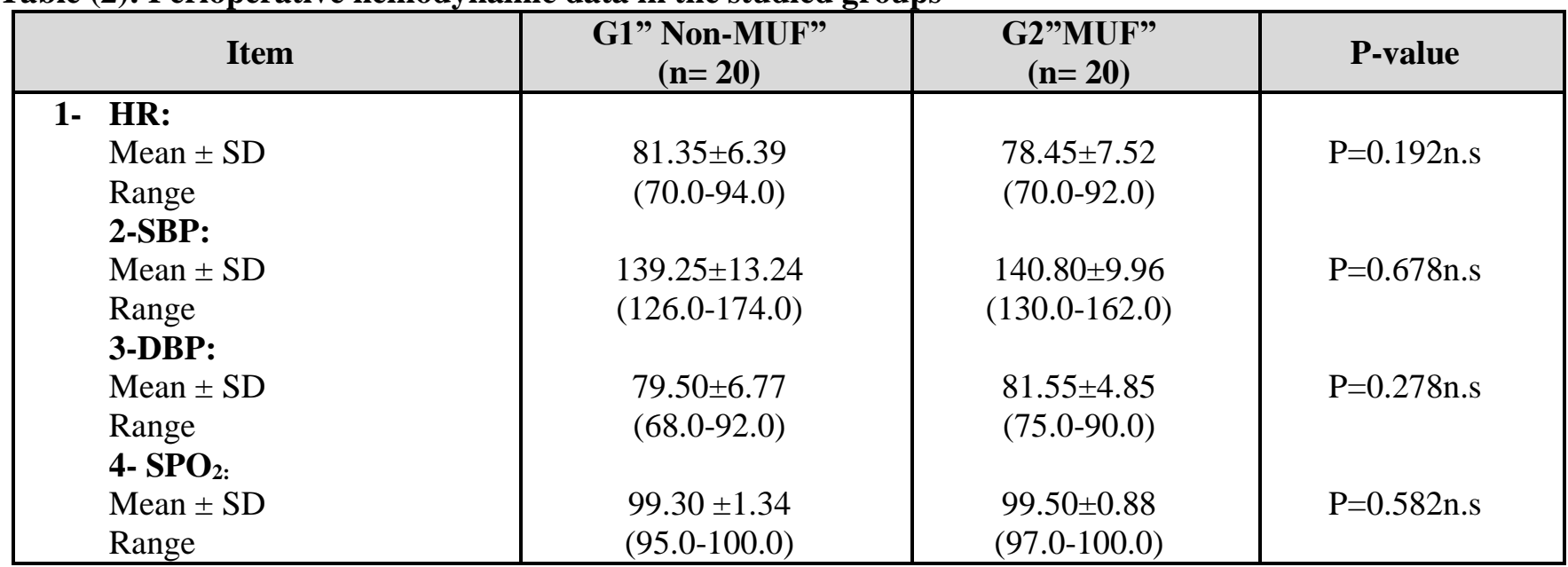

Abbreviations: Group1: without modified ultra-filtration.Group2: with modified ultrafiltration. HR: heart rate, SBP: systolic blood pressure, DBP: diastolic blood pressure, SPO2: arterial oxygen saturation. P-value is considered significant at $<0.05$.

There was no significant difference $(\mathrm{P}>0.05)$ between the two studied groups regarding used fresh blood units, whereas there were significant lower packed RBCs units used in the MUF group than the Non-MUF group $(\mathrm{P}<0.05)$ as in Table 3. 
Table (3): Intraoperative blood component requirements in the studied groups

\begin{tabular}{|l|c|c|c|}
\hline \multicolumn{1}{|c|}{ Item } & G1" Non-MUF" $(\mathbf{n = 2 0})$ & G2"MUF" $(\mathbf{n = 2 0})$ & P-value \\
\hline 1-Fresh blood units & 1 & 1 & \\
Median & $0-3$ & $(0.0-2.0)$ & \\
$\begin{array}{l}\text { Range } \\
\text { 2-Packed RBCs units }\end{array}$ & 2 & 0 & $\mathrm{P}=0.250$ \\
$\begin{array}{l}\text { Median } \\
\text { Range }\end{array}$ & $(0.0-4.0)$ & $(0.0-4.0)$ & $\mathrm{P}=0.022$ \\
\hline
\end{tabular}

Abbreviations: Group1: without modified ultra-filtration. Group2: with modified ultrafiltration, RBCs : Red Blood Cells, P-value is considered significant at $<0.05$

There was no significant difference $(\mathrm{P}>0.05)$ between the two study groups in each of ICU stay \& duration of mechanical ventilation, Table 4 .

Table (4): Post-operative ICU stay \& duration of mechanical ventilation in the studied groups

\begin{tabular}{|l|c|c|c|}
\hline \multicolumn{1}{|c|}{ Item } & $\begin{array}{c}\text { G1" Non-MUF" } \\
(\mathbf{n = 2 0})\end{array}$ & $\begin{array}{c}\text { G2"MUF" } \\
(\mathbf{n = 2 0})\end{array}$ & P-value \\
\hline $\begin{array}{l}\text { 1-ICU stay "days" } \\
\begin{array}{l}\text { Median (Range) } \\
\text { 2-Duration of Mechanical Ventilation "hours" }\end{array}\end{array}$ & $2(1.0-7.0)$ & $1(1.0-7.0)$ & $\mathrm{P}=0.120$ \\
Median (Range) & $3(2.0-24.0)$ & $2(2.0-8.0)$ & $\mathrm{P}=0.165$ \\
\hline
\end{tabular}

Abbreviations: Group1: without modified ultra-filtration.Group2: with modified ultrafiltration. ICU: intensive care unit. P-value is considered significant at $<0.05$

Regarding serum creatinine levels, the preoperative and $2 \mathrm{~h}$ postoperative serum creatinine were not statistically different between the two studied groups ( $>0.05$ ), while in the non-MUF group, there was a significant increase $(\mathrm{P}<0.001)$ in the $2 \mathrm{~h}$. post-operative s. Creatinine level compared with the pre-operative level as shown in Table 5.

Table (5): Serum creatinine level in the studied groups

\begin{tabular}{|c|c|c|c|}
\hline Item & $\begin{array}{c}\text { G1" Non-MUF" } \\
(n=20)\end{array}$ & $\begin{array}{c}\text { G2" MUF" } \\
(n=20)\end{array}$ & P-value ${ }^{1}$ \\
\hline $\begin{array}{l}\text { 1- Pre-operative serum creatinine (mg/dl) } \\
\text { Median(Range) } \\
\text { 2- 2h. Post-operative serum creatinine (mg/dl) } \\
\text { Median(Range) } \\
\text { p-value }{ }^{2}\end{array}$ & $\begin{array}{c}1.1(0.8-1.3) \\
1.3(0.9-3.3) \\
\mathbf{0 . 0 0 1}\end{array}$ & $\begin{array}{c}1.1(0.8-3.0) \\
0.070\end{array}$ & 0.294 \\
\hline
\end{tabular}

Abbreviations: Group1; without modified ultra-filtration.Group2; with modified ultrafiltration. P-value ${ }^{1}$ : P value between groups; $\mathrm{p}$-value ${ }^{2}$ : P value intra groups; $\mathrm{P}$ value is considered significant at $<0.05$

Regarding serum NGAL, the Preoperative and $2 \mathrm{~h}$. Post-operative serum NGAL was not statistically different $(\mathrm{P}>0.05)$ between the two studied groups. However, there was a significant increase $(\mathrm{P}<0.001)$ in the $2 \mathrm{~h}$. postoperative serum NGAL levels in both groups compared with the pre-operative levels and the percentage of change in the MUF group $(131.13 \%)$ was significantly less $(\mathrm{P}<0.02)$ than the Non-MUF group $(164.46 \%)$ (Table 6$)$.

Table (6): Serum NGAL level in the studied groups

\begin{tabular}{|c|c|c|c|}
\hline Item & $\begin{array}{c}\text { G1" Non-MUF" } \\
(n=20)\end{array}$ & $\begin{array}{l}\text { G2" MUF" } \\
(n=20)\end{array}$ & P-value ${ }^{1}$ \\
\hline $\begin{array}{l}\text { 1- Preoperative NGAL (ng/ml) } \\
\text { Median(Range) } \\
\text { 2-2h. Post-operative NGAL (ng/ml) } \\
\text { Median(Range) } \\
\text { p-value }{ }^{2}\end{array}$ & $\begin{array}{c}80(30.0-140.0) \\
90(46.0-927.0) \\
<0.001 *\end{array}$ & $\begin{array}{c}70(30.0-135.0) \\
78(44-865) \\
<0.001 * \\
\end{array}$ & $\begin{array}{l}\mathrm{P}=0.088 \\
\mathrm{P}=0.126\end{array}$ \\
\hline
\end{tabular}

Abbreviations: Group1: without modified ultra-filtration. Group2: with modified ultrafiltration; NGAL: Serum Neutrophil gelatinase-associated Lipocalin; P-value1: P value between groups; p-value2: P-value intra groups; P value is considered significant at $<0.05$.

\section{Effect of modified ultrafiltration on acute kidney injury biomarkers and clinical outcome:}

There was no significant difference $(\mathrm{P}>0.05)$ between AKI and non-AKI patients in pre. Operative levels while the postoperative Creatinine levels were significantly higher $(\mathrm{P}<0.04)$ in AKI than non-AKI patients in the MUF group (Table 7). 
Table (7): Serum creatinine in the MUF group.

\begin{tabular}{|l|c|c|c|}
\hline \multicolumn{1}{|c|}{ Item } & $\begin{array}{c}\text { AKI } \\
(\mathbf{n}=\mathbf{4})\end{array}$ & $\begin{array}{c}\text { Non AKI } \\
(\mathbf{n}=\mathbf{1 6})\end{array}$ & P-value \\
\hline 1- Preoperative creatinine. & $0.95 \pm 0.05$ & $1.05 \pm 0.16$ & $\mathrm{P}=0.386 \mathrm{n} . \mathrm{s}$ \\
2- 2h Post-operative creatinine & $1.47 \pm 0.35$ & $1.16 \pm 0.11$ & $\mathrm{P}<0.04 *$ \\
\hline
\end{tabular}

Abbreviations; AKI: Acute Kidney Injury; P-value is considered significant at $<0.05$

\section{DISCUSSION}

Our study found that there is a significant increase in the 2-hours postoperative serum NGAL level in both MUF and non-MUF groups compared with the preoperative levels with a higher percentage of change in the non MUF group. While only in the non-MUF group, 2-hours post-operative s. Creatinine level is significantly increased compared with the preoperative level. Furthermore, in the MUF group the pre and 2-hours postoperative s.NGAL and the postoperative creatinine levels are significantly higher in the AKI than in non AKI patients.

For over a century, the measurement of serum creatinine, a biomarker of glomerular filtration, has been a mainstay of clinical laboratory testing and served as the primary method for quantifying renal function. These creatinine-based estimates of renal function are focused on glomerular filtration and do not adequately account for structural renal tubular injury, which may be extensive in the setting of AKI. The past several years have seen a large number of investigations seeking novel biomarkers of $\mathrm{AKI}{ }^{(5)}$.

The identification of novel biomarkers of AKI for early diagnosis is particularly important. As a member of the lipocalin superfamily, NGAL was considered to be one of the ideal and important biomarkers in the diagnosis of AKI ${ }^{(6)}$.

Zhang et $\boldsymbol{a l}$. ${ }^{(7)}$ concluded that evaluating NGAL levels in critically ill patients may improve the early detection of AKI and facilitate early treatment and improve prognosis.

In the present study the Preoperative and $2 \mathrm{~h}$. Post-operative serum NGAL was not statistically different $(\mathrm{P}>0.05)$ between the MUF and the NonMUF groups. Furthermore, There was a significant increase $(\mathrm{P}<0.001)$ in the $2 \mathrm{~h}$. post-operative serum NGAL levels in both groups compared with the preoperative levels and the percentage of change in the MUF group (131.13\%) was significantly less $(\mathrm{P}<0.02)$ than the Non-MUF group (164.46\%).

The available data is contradictory with several studies showing no difference in plasma markers of inflammation and coagulation. Whereas 2 studies reported that cytokine concentrations are reduced by MUF. one study found only transient effects of MUF on the level of proinflammatory cytokines (e.g. IL-6 and IL-8) during the immediate post-CPB period, without effect on the levels of antiinflammatory cytokines levels (e.g. IL-1o and IL-1ra) (8).
Another study found decreased serum levels of adhesion molecules, IL- 6 , and IL-8, but only after hypothermic $\mathrm{CPB}$; such effects were not detected in normothermic $\mathrm{CPB}{ }^{(9)}$. It is noteworthy that reduced levels of inflammatory mediators were not associated with improvements in clinical outcome. These data suggest that the beneficial effects of MUF are achieved by mechanisms further to the removal of inflammatory mediators from the plasma.

Additionally, the pre-operative, $2 \mathrm{~h}$ postoperative S. NGAL, and the postoperative creatinine were significantly higher in AKI than non-AKI patients in the MUF group. This agrees with Vives $\boldsymbol{e t}$ al. (1), who reported Patients with an early higher urinary and plasma NGAL levels are most likely to be diagnosed of AKI.

NGAL has been demonstrated to be a highly sensitive and specific predictor of CSA-AKI. Urinary NGAL was demonstrated as an early biomarker of AKI after CPB, increasing 25-fold within $2 \mathrm{~h}$ and declining $6 \mathrm{~h}$ after surgery. This promoted the use of urine NGAL as an indicator to forecast subclinical CSA-AKI ${ }^{(10)}$.

McIlroy and his colleagues ${ }^{(10)}$ in a multicenter pooled analysis of prospective studies showed that in the absence of diagnostic increases in serum creatinine, NGAL detected patients with likely subclinical AKI who have an increased risk of adverse outcomes. Therefore, NGAL levels may detect AKI 24-72 hrs earlier than S.creatinine and has also a prognostic impact.

Additionally, Data from a meta-analysis on 2,322 patients suffering from AKI related to cardiac disease, suggest that patients with a higher NGAL, are most likely to develop adverse outcomes, even when creatinine is normal. Hence, it is suggested that subclinical AKI may be diagnosed by this biomarker (11).

Fadel $\boldsymbol{e t}$ al. ${ }^{(12)}$ reported that mean plasma NGAL levels showed highly significant elevations at 2,12 , and $24 \mathrm{~h}$ after surgery $(p<0.0001)$ in patients who developed AKI compared to patients who did not. A significant correlations $(p<0.0001)$ were found between plasma NGAL and AKI at 2, 12, and $24 \mathrm{~h}$ after surgery. A cut-off level of $100 \mathrm{ng} / \mathrm{ml}$ at $2 \mathrm{~h}$, and $125 \mathrm{ng} / \mathrm{ml}$ at $12 \mathrm{~h}$ post-operatively both recorded the highest accuracy, being $95 \%$ accurate, with sensitivity of $100 \%$ and $89.5 \%$ respectively, and specificity of $90.5 \%$ and $100 \%$ respectively. 
Vanmassenhove et al. ${ }^{(13)}$ in a recent metaanalysis that included 74 studies, identified NGAL as the biomarker with best discriminative performance for early diagnosis of cardiac surgery associated AKI and for outcome prediction.

In our results, there is a significant decreased intraoperative urine output in the AKI patients compared with non-AKI patients which are disagreed with Karim et al. ${ }^{(14)}$ who reported in their study that the mean intraoperative urine output was not different in CSA-AKI positive and negative cases. That might be attributed to using different perfusionist protocols.

\section{CONCLUSION}

AKI after cardiac surgery is independently associated with a significant increase in morbidity, mortality, and health-care costs. Kidney protection strategies to prevent AKI during cardiac surgery (including the use of MUF) are not yet conclusive and using MUF as a routine measure in adult valvular surgery is not warranted.

\section{REFERENCES}

1. Vives M, Hernandez A, Parramon F et al. (2019): Acute kidney injury after cardiac surgery: prevalence, impact, and management challenges. Int $\mathbf{J}$ Nephrol Renovasc Dis., 12: 153-166.

2. Hoste E, Bagshaw S, Bellomo $\mathrm{R}$ et al. (2015): Epidemiology of acute kidney injury in critically ill patients: the multinational AKI- EPI study. Intensive Care Med., 41:1411-1423.

3. Chawla L, Amdur R, Shaw A et al. (2014): Association between AKI and long- term renal and cardiovascular outcomes in United States veterans. Clin J Am Soc Nephrol., 9:448-456.

4. Liangos $\mathrm{O}$, Tighiouart $\mathrm{H}$, Perianayagam $\mathrm{M}$ et al. (2009): Comparative analysis of urinary biomarkers for early detection of acute kidney injury following cardiopulmonary bypass. Biomarkers, 14: 423-431.
5. Koyner J, Parikh C (2013): Clinical utility of biomarkers of AKI in cardiac surgery and critical illness.Clin J Am Soc Nephrol., 8:1034-1042.

6. Veighey K, MacAllister R (2015): Clinical applications of remote ischemic preconditioning in native and transplant acute kidney injury. Pediatr Nephrol., 30:1749-1759.

7. Zhang J, Han J, Liu J et al. (2017): Clinical significance of novel biomarker NGAL in early diagnosis of acute renal injury. Exp Ther Med., 14(5): 5017-5021.

8. Grunenfelder J, Zund G, Schoeberlein A et al. (2000): Modified ultrafiltration lowers adhesion molecule and cytokine levels after cardiopulmonary bypass without clinical relevance in adults. Eur J Cardiothoracic Surg., 17:77-83.

9. Friesen R, Campbell D, Clarke D (1997): Modified ultrafiltration attenuates dilutional coagulopathy in pediatric open-heart operations. Ann Thorac Surg., 64: 1787.

10. McIlroy D, Wagener G, Lee H (2010): Neutrophil gelatinase-associated lipocalin and acute kidney injury after cardiac surgery: the effect of baseline renal function on diagnostic performance. Clin J Am Soc Nephrol., 5:211-219.

11. Haase M, Devarajan P, Haase-Fielitz A et al. (2011): The outcome of neutrophil gelatinase-associated lipocalin-positive subclinical acute kidney injury: a multicentre pooled analysis of prospective studies. J Am Coll Cardiol., 57(17): 1752-61.

12. Fadel F, Abdel Rahman A, Mohamed M et al. (2012): Plasma neutrophil gelatinase-associated lipocalin as an early biomarker for prediction of acute kidney injury after cardio-pulmonary bypass in pediatric cardiac surgery. Arch Med Sci. , 8(2): 250-255.

13. Vanmassenhove J, Vanholder $R$, Nagler $E$ et al. (2013): Urinary and serum biomarkers for the diagnosis of acute kidney injury: an in-depth review of the literature. Nephrol Dial Transplant, 28: 254-273.

14. Karim H, Yunus M, Saikia M et al. (2017): Incidence and Progression of Cardiac Surgery-associated Acute Kidney Injury and its Relationship with Bypass and Cross Clamp Time. Ann Card Anaesth., 20(1): 22-27. 